sertation is the first of its kind in this country, but no serious student of agriculture, and particularly of its relation to the trend of commercial and social development, will fail to derive profit from Mr. Rutter's book. It represents an immense amount of painstaking work, such as can only be appreciated by one who has himself tried to reduce to some common denominator the scattered statistics and information about various countries, and it should find an interested public now that agriculture is being systematically studied and taught in the United Kingdom.

A. D. H.

\section{ACTUAL EIECTROCHEMISTRY.}

Applied Electrochemistry. By Prof. M. de Kay Thompson. Pp. xii +329 . (New York: The Macmillan Co.; London: Macmillan and Co., Ltd., r9i I.) Price 9s. net.

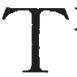
HERE have been many books written on this subject, and they are apt to come under two heads, the purely scientific, in which the principles of modern electrolytic theory are discussed very fully, without much information as to their practical application; and the purely commercial, in which the various industries are described, with views of the various kinds of plants. A third variety might be included which discusses all sorts of processes, most of them never having had any real existence, the information and illustrations being taken entirely from the rather imaginative patent literature of the subject.

Dr. Thompson does not begin with an elaborate treatise on what is known as "theory"-he assumes that the reader is well acquainted with the first principles; he merely refers to them, and utilises them and their formula as he needs them. He discusses first such subjects as electrochemical analysis. This chapter is a mere sketch, but a good sketch of the subject, which is now far too large to be treated so shortly. A reader would get a good idea of this sort of analysis from the book, but in order to utilise it he would have to study a special treatise. Electro-plating is treated very shortly, but in a refreshingly common-sense way. This common sense runs through the whole book. It is not necessary to give a list of the contents; it may be taken that the book gives a concise account in clear and scientifically accurate language of all the important electrolytic and allied processes in commercial use, and that it does not discuss all sorts of inventions that have been failures in practice. It is a great pity that such failures are not discussed as failures, the reasons of their non-success being given. These would be very valuable, but most difficult to give. In science, both applied and unapplied, NO. 22 I 5 , VOL. 8g] people are far too reticent about failures, yet there is much to be learned from them. Dr. Thompson deals very fully with the electrolysis of salt in the wet way, and one of the most interesting chapters is that on ozone. Though there are books on ozone there is not much trustworthy information, and this chapter is very welcome.

The book is American, with heavy American paper but no aggressive American spelling. It has involved a great deal of literary work, and references are always given. There can be little doubt that the amount of matter read and rejected was greater than that utilised. The work is, in short, an admirable, intelligent account of the electrochemical industry as it exists.

\section{J. Swinburne.}

\section{A TREATISE ON CHOLERA.}

Cholera and its Treatment. By Prof. L. Rogers. pp. xiv +236 . (London: Henry Frowde and Hodder and Stoughton, I9ri.) Price ros. $6 d$. net.

7 HIS book is a complete treatise on cholera, containing all the essentials of the subject without being over-burdened with details which are of little practical importance. The first and second chapters deal with the history of cholera epidemics and their lessons, and the epidemiology of the disease. In chapter iii. the etiology and prophylaxis of the disease are discussed, and it commences with a description of the specific organism of the disease, the comma bacillus of Koch, which the author fully accepts as the cause of cholera. In this section we should have been glad to see a somewhat fuller discussion of the significance of the rarious cholera-like comma bacilli which have been isolated during the last few years. The hypothesis of Emmerich that cholera is a condition of nitrite poisoning is not accepted by the author. Prophylactic vaccination by means of cholera vaccine is regarded as being of considerable value, and the measures to be taken for the disinfection of infected wells are described.

Chapter iv. deals with the clinical aspects of cholera and its diagnosis, chapter $v$. with the morbid anatomy and pathology. In the final chapter the treatment is discussed at some length, and to many this will be considered the most important part of the book, for the author himself has contributed in no small measure to the rational treatment of this terrible malady. Dr. Rogers is entirely opposed to the purgation method except at the very early stage and before the onset of the typical watery evacuations, the "rice-water stools." Opium also has to be used with extreme caution. Injections of saline fluid, either per rectum, subcutaneously, intraperitoneally, or 